\title{
Testing for Rational Bubbles in the Commodity Market
}

\author{
Tadahiro Nakajima (Corresponding author) \\ The Kansai Electric Power Company, Incorporated \\ 6-16, Nakanoshima 3-chome, Kita-Ku, Osaka, 530-8270, Japan \\ Tel: 81-6-6441-8821Ｅ-mail: nakajima.tadahiro@a4.kepco.co.jp
}

Shigeyuki Hamori

Faculty of Economics, Kobe University

2-1, Rokkodai, Nada-Ku, Kobe, 657-8501, Japan

Tel: 81-78-803-7245Ｅ-mail: hamori@econ.kobe-u.ac.jp

Received: September 6, 2012

Accepted: September 24, 2012

Online Published: September 26, 2012

doi:10.5430/afr.v1n2p101

URL: http://dx.doi.org/10.5430/afr.v1n2p101

\begin{abstract}
In order to hedge price-fluctuation risks, to derive fair prices, and to operate funds as a new asset class, both expectations and concerns about commodity markets have been increasing. This paper proposes a sufficient condition for the absence of rational bubbles in the commodity market: that the first differences of real prices are stationary. This condition is proposed on the assumption that products of the convenience yield and the real prices are stationary. By applying this approach to the US crude oil and natural gas markets from 3 January 2007, to 30 December 2011, the absence of rational bubbles in both markets can be verified. One should interpret these large price fluctuations as caused by much larger income elasticity than price elasticity. These prices reflect the fundamental values of these commodities.
\end{abstract}

Keywords: Rational bubbles, Commodity market, Convenience yield, Crude oil price, Natural gas price

\section{Introduction}

\subsection{Rational bubbles}

The fundamental value of a security can be defined as the present value of all future cash flows associated with that security, according to standard financial asset pricing theory. In general, the difference between the actual price of an asset and its fundamental value is called a bubble. Since in an efficient market, all information will be immediately reflected in prices, only unexpected information would be able to create price variances. However, stock price volatilities may sometimes increase stupendously even in the complete absence of surprising news. This could be because market players often trade in securities in line with reasonable expectations of price fluctuation, although they themselves may have reasonable and sufficient knowledge of the fundamental value. This sort of behavior causes rational bubbles. Furthermore, sometimes securities are traded without a rational judgment of fundamental value, and such behavior could cause irrational bubbles.

Since Blanchard and Watson (1982) initially proposed the model of rational-expectation bubbles, various models and tests have been studied and introduced. Many papers have also examined the presence of rational bubbles in actual financial markets, addressing stock prices, stock indices, exchange rates and hyper-inflation, among other matters. However, few papers have investigated rational bubbles in areas other than financial markets: Chan, Lee and Woo (2001), Chen (2001) and Xiao (2007) analyzed the real estate market; Bertus and Stanhouse (2001) examined rational speculative bubbles in the gold market; and Gilbert (2010) analyzed bubbles in the crude oil, aluminum, copper, nickel, wheat, corn and soybean markets.

Campbell and Shiller (1987), Diba and Grossman (1988), Crain (1993), Campbell (2000) and Fukuta (2002) propose certain techniques to test whether the features of rational bubbles are consistent with the processes inherent in certain variables (e.g., dividends, prices, returns and fundamental value). The proposed techniques address the restrictions necessary for the absence of rational bubbles. Therefore, any conclusion that these necessary conditions have not been satisfied would determine the existence of rational bubbles. In contrast to these studies, Fukuta (1996) considers 
the sufficient conditions for the absence of rational bubbles in the stock market. A conclusion that these sufficient conditions have been met would determine the absence of rational bubbles. Given these, the necessary conditions approach is useful to determine the presence of rational bubbles, and the sufficient conditions approach is useful to determine the absence of rational bubbles.

\subsection{Commodity markets}

Tangible assets such as energy, resources, metals and grain are called commodities; one can trade these assets in not only their original form but also their various derivative forms on the New York Mercantile Exchange (NYMEX), the Chicago Board of Trade (CBOT), the London Metal Exchange (LME), the Intercontinental Exchange (ICE) and the like.

Since the intrinsic value of a commodity is meant to be consumed, the features of its price fluctuations differ from those of a financial asset. In particular, it is well known that the prices of futures have a characteristic term structure. Commodity prices are formed by considering not only supply-and-demand trends, stocks, seasonality and speculative trading but also carrying costs and consumption convenience.

Recently, both expectations and concerns about commodity markets have been increasing, in general, for three reasons. First, the demand for derivatives - such as futures, options and spreads - is growing; these derivatives are used principally to hedge price-fluctuation risks in raw material and final product markets. Commodity prices are influenced by not only the demand-and-supply balance but also political, economic and weather conditions. Besides, large fluctuations in commodity prices have a significant impact on the profitability of companies handling those commodities. Therefore, companies use commodity markets as a means to mitigate their price-fluctuation risks.

Second, commodity markets are expected to derive fair prices. Since a large number of players-including private and institutional investors - are involved in commodity markets, in addition to companies that actually trade in tangible assets, a significant amount of data on listed commodities are aggregated. As a result, one can expect the formation of fair and clear prices. Moreover, one can use these prices as reliable benchmarks.

Third, commodities have gained importance as a new asset class in fund operations. Commodities are considered to have a low degree of correlation with traditional financial assets such as stocks and bonds; they are also considered a strong hedge against inflation. Therefore, they are increasingly important as a class of alternative investments. Hence, commodities are often included in the asset portfolio of firms along with conventional investments.

\subsection{Motivation and objective}

Previous studies have scarcely examined the bubble in commodity markets, which are garnering much attention; on the other hand, the bubble in traditional financial markets has been very frequently studied for about 20 years, through various empirical approaches. Moreover, the sufficient conditions for the absence of rational bubbles in commodity markets have not been tested. There is no dividend or theoretical fundamental value in the commodity market. One can consider this an obstacle to the fruitful study of bubbles in the commodity market.

Consequently, by extending Fukuta's (1996) model to the commodity market, this paper proposes a sufficient condition for the absence of rational bubbles in the commodity market. By applying this approach to the West Texas Intermediate (WTI) and the Henry Hub (HH) future prices on the NYMEX, one can conclude that there is no rational bubble therein.

The remainder of this paper is organized as follows. Section 2 explains the methodology in applying Fukuta's (1996) model to the commodity market. Section 3 provides an examination of the US crude oil and natural gas markets, and, finally, Section 4 summarizes the contributions of this study.

\section{Approach to the commodity market}

\subsection{Fukuta's model}

Fukuta (1996) states that if the risk premium and real interest rates are stationary, the stationarity of the first differences of real stock prices is a sufficient condition for the absence of rational bubbles.

Consider the following standard noarbitrage condition in the stock market:

$$
\pi(t)(1+r(t)+\rho(t))=E\left(\delta(t+1)+\pi(t+1) \mid I_{t}\right)
$$

where $\pi(t)$ is the real stock price at the beginning of period $t, r(t)$ is the real risk-free interest rate at period $t$, $\rho(t)$ is the risk premium at period $t, \delta(t+1)$ is the real dividend paid to the owner at the end of period $t$, and $E\left(\cdot \mid I_{t}\right)$ is the market's expectations conditional on information available at period $t$. 
If $r(t)$ and $\rho(t)$ are stationary, both the variables have unconditional means. One can then consider $r$ and $\rho$ as the unconditional means of $r(t)$ and $\rho(t)$, respectively, and rewrite Equation 1 as

$$
\xi_{1}(t)-\xi_{2}(t)+(1+r+\rho) \pi(t)=E\left(\delta(t+1)+\pi(t+1) \mid I_{t}\right)
$$

where $\xi_{1}(t)=\pi(t)(r(t)+\rho(t))$ and $\xi_{2}(t)=\pi(t)(r+\rho)$. Equation 2 can be rewritten as

$$
\pi(t)=\beta\left(E\left(\delta(t+1)+\pi(t+1) \mid I_{t}\right)-\xi_{1}(t)+\xi_{2}(t)\right)
$$

where $\beta=(1+r+\rho)^{-1}$. Next, applying a recursive forward substitution to Equation 3, one can derive the following equation:

$$
\begin{gathered}
\pi(t)=E\left(\sum_{\theta=1}^{\infty} \beta^{\theta+1}\left(\delta(t+\theta+1)-\xi_{1}(t+\theta)+\xi_{2}(t+\theta)\right) \mid I_{t}\right) \\
+\lim _{\theta \rightarrow \infty} \beta^{\theta+1} E\left(\pi(t+\theta+1) \mid I_{t}\right)
\end{gathered}
$$

where the first term on the right-hand side is the fundamental component of the share price, and the second term is the rational bubble component. Therefore, the absence of a rational bubble means that

$$
\lim _{\theta \rightarrow \infty} \beta^{\theta+1} E\left(\pi(t+\theta+1) \mid I_{t}\right)=0
$$

If the first difference of a real stock price is stationary, then one can conclude that

$$
\Delta \pi(t)=\mu+\varepsilon(t)
$$

where $\Delta \pi(t)$ is the first difference of a real stock price, $\mu$ is the drift term, and $\varepsilon(t)$ is the stationary error term. One can rewrite Equation 6 as

$$
\pi(t)=\pi(t-1)+\mu+\varepsilon(t)
$$

Equation 7 can be rewritten as

$$
\pi(t+\theta+1)=\pi(t)+\mu(\theta+1)+\sum_{\omega=t+1}^{t+\theta+1} \varepsilon(\omega)
$$

Finally, by substituting Equation 8 in the second term on the right-hand side of Equation 4, one can obtain the following rational-bubble component:

$$
\lim _{\theta \rightarrow \infty} \frac{\pi(t)+\mu(\theta+1)+\sum_{\omega=t+1}^{t+\theta+1} \varepsilon(\omega)}{(1+r+\rho)^{\theta+1}}
$$

Equation 9 converges to 0 , because the numerator grows more slowly than the denominator as $\theta$ approaches infinity. Hence, one will find the absence of rational-bubble behavior.

\subsection{Convenience yield}

When testing for the absence of rational bubbles in the commodity market through Fukuta's (1996) approach, the key concept is convenience yield. Financing cost is not the only factor that can cause differences between futures and spot prices; the costs and benefits of holding a commodity asset that can be consumed immediately also can affect futures and spot prices. In other words, the higher the inventory cost becomes, the more sharply the value of futures increases, relative to spot values. Conversely, the larger the advantage of a real asset that can be utilized immediately becomes, the more substantially the value of futures decreases in relation to spot values. This possession value, expressed in yield form, is defined as convenience yield; it is the earnings that only the spot holder can obtain. Similarly, in the stock market, one cannot acquire dividends with futures over the long term; one can receive dividends only on stocks. Therefore, convenience yield in the commodity market can be interpreted as dividend yield in the stock market. However, it is difficult to analyze a convenience yield directly. Therefore, we estimate a convenience yield by calculating backward from the difference between the future and spot prices.

Supposing $s(t)$ is the spot price at the beginning of period $t$, the cost to keep $s(t)$ for one term can be written as $r(t)+h(t)-c(t)$, where $r(t)$ is the risk-free interest rate, $h(t)$ is the holding cost expressed by yield, and $c(t)$ is the convenience yield at period $t$. Using these, $f(t)$, the future price at the beginning of period $t$, whose maturity is $T$, can be described as follows:

$$
f(t)=s(t) e^{(r(t)+h(t)-c(t))(T-t)}
$$

Since both $h(t)$ and $c(t)$ are unobservable, $c(t)-h(t)$ can be defined as the net convenience yield $y(t)$. Substituting $y(t)=c(t)-h(t)$ into Equation 10, one can solve $y(t)$ as follows:

$$
y(t)=r(t)-\frac{1}{T-t} \ln \frac{f(t)}{s(t)}
$$

With Equation 11, one can calculate $y(t)$ from $f(t)$ and $s(t)$, both of which are observable variables. Equation 11 is described under continuous compounding. By conversion, one can use $e^{y(t)}-1$ as the net convenience yield 
under discrete compounding. Therefore, the expected holding return in the commodity market is $s(t)\left(e^{y(t)}-1\right)$.

2.3 Application to commodity market

Before investigating the sufficient condition for the absence of rational bubbles in the commodity market, we need to examine the assumption that both the real risk-free interest rate and risk premium are stationary. From Equation 1, which implies that the real expected holding return on a stock is equal to $\pi(t)(r(t)+\rho(t))$, one can conclude that if the dividend were stationary, then $\pi(t)(r(t)+\rho(t))$ would be stationary in the stock market. By analogy, this assumption in the commodity market can be read in a different way, as the stationary process of real $s(t)\left(e^{y(t)}-1\right)$. In other words, one can advance the test for the absence of rational bubbles in $s(t)$, if the unit root hypothesis of real $s(t)\left(e^{y(t)}-1\right)$ can be rejected.

A sufficient condition for the absence of rational bubbles in the stock market is that the first difference of a real stock price is stationary. Similarly, in the commodity market, by examining the stationarity status of the first difference of real $s(t)$, one can verify the presence of rational bubbles. If the unit root hypothesis can be rejected, one cannot conclusively state that $s(t)$ contains a rational bubble.

\section{Examination of US crude oil and natural gas markets}

Since 2007, most of the markets have exhibited unusual trends and high volatility because of the subprime mortgage crisis that year, the Lehman crisis in 2008 and the current European sovereign debt crisis. Furthermore, since 2007, the concern for energy supply due to geopolitical instability has been swelling, the energy consumption of unstable emerging countries has been increasing and the inflow of speculative funds into energy markets due to expansionary monetary policy has been escalating. Therefore, the volatility in energy markets has been extremely high during this period.

Our examination of rational bubbles in the US crude oil and natural gas markets is limited to the period from 3 January 2007, to 30 December 2011.

\subsection{Data}

We use daily data from 3 January 2007 to 30 December 2011, for this study. Crude oil prices, cited in US dollars per barrel, are the closing prices of future contracts specifying the earliest delivery date (future contract 1) and the successive delivery months (following future contract 1) (future contract 2) of WTI in NYMEX. Natural gas prices, cited in US dollars per million British thermal units, are the closing prices of future contracts specifying the earliest delivery date (the future contract 1 ) and the successive delivery months (following future contract 1) (future contract 2) of HH in NYMEX. Risk-free interest rates, given as percentage values per annum, are the market nominal yields on the US treasury securities at one-month constant maturities.

The discount rate to realize the value of prices and rates, given as an annual percentage change, is the US Consumer Price Index (CPI).

Datasets containing crude oil prices, natural gas prices, risk-free interest rates and discount rates were obtained from the websites of the US Department of Energy's Energy Information Administration (Note 1), the US Board of Governors of the Federal Reserve System (Note 2) and the US Department of Labor's Bureau of Labor Statistics (Note 3).

\subsection{Empirical results}

The mutual relationships between futures with different maturities are described as follows:

$$
Y(t)=r(t)-\frac{1}{T_{2}-T_{1}} \ln \frac{F\left(t, T_{2}\right)}{F\left(t, T_{1}\right)}
$$

where $Y(t)$ is the continuous convenience yield of $F\left(t, T_{1}\right), F\left(t, T_{1}\right)$ is the price of future contract 1 , and $F\left(t, T_{2}\right)$ is the price of future contract 2 at date- $t$.

Hence, one can express the real expected holding return on future contract 1, real_R $(t)$, as follows:

$$
\text { real_R } R(t)=\frac{1}{C P I(t)} S(t)\left(e^{Y(t)}-1\right)
$$

where $\operatorname{CPI}(t)$ is the CPI for the month containing date- $t$, assuming that the CPI for January 2007 is unity.

The stationarity status of real_R $(t)$ is then tested. Various types of unit root tests have been developed; however, it is not easy to say which unit root test technique dominates in terms of power. Therefore, we use the augmented Dickey and Fuller (ADF) test, one of the most frequently used authorization techniques. We determine the appropriate lag orders by minimizing the Schwarz information criterion (SIC). Table 1 lists the summary statistics of real_R $R$, and Table 2 reports the results obtained by applying the ADF test to these variables. The unit root hypothesis for each variable is rejected in all cases at the $1 \%$ significance level. Therefore, it is possible to examine 
the sufficient condition for the absence of rational bubbles.

The first differences of real $F\left(t, T_{1}\right)$ are then calculated to test for the absence of rational bubbles.

$$
\Delta\left(\text { real_}_{-} F\left(t, T_{1}\right)\right)=\frac{1}{C P I(t)} F\left(t, T_{1}\right)-\frac{1}{C P I(t-1)} F\left(t-1, T_{1}\right)
$$

The summary statistics of $\Delta\left(\right.$ real_$\left.F\left(t, T_{1}\right)\right)$ are shown in Table 1 . The results of the ADF unit root test applied to each variable are reported in Table 3. Appropriate lag orders are determined by minimizing the SIC. We could find that, in all cases, the results for each series showed a trend toward rejecting the unit root hypothesis. One can therefore conclude the absence of rational bubbles in both the WTI and HH future contract 1 markets.

\subsection{Considerations}

If the noarbitrage condition Equation 1 is not satisfied, or the crude oil and natural gas markets are not efficient, the prices might contain irrational bubbles. However, this paper does not study whether or not the crude oil and natural gas markets are efficient; this problem we leave for future studies.

Our results indicate that there was no rational bubble in the WTI and HH future prices between the beginning of 2007 and the end of 2011. Figure 1 provides the time plots of these variables. Large price fluctuations can be observed. However, one should not assume from this that a bubble has occurred and disappeared. One should interpret these large price fluctuations as caused by much larger income elasticity than price elasticity. In fact, even if the price of crude oil and natural gas soared from 2007 to 2008, the consumption did not decline because the world economy grew greatly during this period. Moreover, when these prices declined from 2008 to 2009, the demand decreased with the economic recession. Table 4 presents the gross world product (GWP), the average price of WTI and $\mathrm{HH}$, and the world demand of crude oil and natural gas from 2007 to 2009. These prices reflect the fundamental values of these commodities.

In this study, the expected holding return does not have a unit root, and therefore, the cointegration methodology cannot be applied. If products of the convenience yield and the prices were not stationary, the cointegration technique could be used in order to test for the presence of rational bubbles in these markets.

\section{Concluding remarks}

This paper first proposes a technique to examine rational bubbles in the commodity market, and the technique is then used to test for rational bubbles in the US crude oil and natural gas markets. The results indicate the absence of rational bubbles in the WTI and HH future markets between the beginning of 2007 and the end of 2011. In particular, the WTI future prices are consistent with Gilbert (2010), which found no evidence for bubbles in the WTI future market over the period 2006-2008.

Campbell and Shiller (1987), Diba and Grossman (1988), Crain (1993), Campbell (2000) and Fukuta (2002) outline the features of rational bubbles in the conventional financial market. However, these studies present only the necessary conditions; therefore, their models cannot directly prove the absence of rational bubbles. On the other hand, Fukuta (1996) shows a sufficient condition for the absence of rational bubbles in the stock market. Although this approach allows for testing for rational bubbles elsewhere, an examination of the commodity market is somewhat peripheral to Fukuta's subject, because Fukuta's sufficient condition requires that the time series of the dividend be analyzed.

Therefore, most previous studies on rational bubbles have examined only traditional financial markets. Rational bubbles in commodity markets have scarcely been investigated to date, because commodities do not have an explicit or substituted dividend.

This study led to the development of a technique to test for rational bubbles in the commodity market by interpreting the dividend yield of a commodity as the convenience yield, from the analogy that the essence of dividends is the holding return.

We expect future research to examine the presence of rational bubbles in commodity markets other than of crude oil and natural gas, because this study's technique is applicable only if a commodity has futures with different contract terms. Moreover, when the expected holding return is not stationary, the presence of bubbles in commodity markets may be investigated by applying the cointegration model, as previous papers have proposed.

\section{References}

Bertus, M., \& Stanhouse, B. (2001). Rational speculative bubbles in the gold futures market: An application of dynamic factor analysis. Journal of Futures Markets, 21, 79-108. http://dx.doi.org/10.1002/1096-9934(200101)21:1<79::AID-FUT4>3.0.CO;2-D 
Blanchard, O. J., \& Watson, M. W. (1982). Bubbles, rational expectations, and financial markets. NBER Working Papers, No: 945. [Online] Available: http://www.nber.org/papers/w0945

Campbell, J. Y. (2000). Asset pricing at the millennium. Journal of Finance, 55, 1515-1568. http://dx.doi.org/10.1111/0022-1082.00260

Campbell, J. Y., \& Shiller, R. J. (1987). Cointegration and tests of present value models. Journal of Political Economy, 95, 1062-1088. [Online] Available: http://www.jstor.org/stable/1833129

Chan, H. L., Lee, S. K., \& Woo, K. Y. (2001). Detecting rational bubbles in the residential housing markets of Hong Kong. EconomicModelling, 18, 61-73. http://dx.doi.org/10.1016/S0264-9993(00)00030-4

Chen, N. K. (2001). Asset price fluctuations in Taiwan: Evidence from stock and real estate prices 1973 to 1992. Journal of Asian Economics, 12, 215-232. http://dx.doi.org/10.1016/S1049-0078(01)00083-5

Crain, R. (1993). Rational bubbles-a test. Journal of Economic Dynamics and Control, 17, 829-846. http://dx.doi.org/10.1016/0165-1889(93)90017-M

Diba, B. T., \& Grossman, H. I. (1988). Explosive rational bubbles in stock prices? American Economic Review, 78,520-530.[Online] Available: http://www.jstor.org/stable/1809149

Fukuta, Y. (1996). Rational bubbles and non-risk neutral investors in Japan. Japan and the World Econnomy, 8, 459-473. http://dx.doi.org/10.1016/0922-1425(96)00222-8

Fukuta, Y. (2002). A test for rational bubbles in stock prices. Empirical Economics, 27, 587-600. http://dx.doi.org/10.1007/s001810100104

Gilbert, C. L. (2010). Speculative influences on commodity futures prices 2006-2008. UNCTAD Discussion papers, No. 197. [Online] Available: http://unctad.org/en/Docs/osgdp20101_en.pdf

Xiao, Q. (2007). What drives Hong Kong's residential property market-A Markov switching present value model. Physica A, 383, 108-114. http://dx.doi.org/10.1016/j.physa.2007.04.092

Notes

Note 1. The US Department of Energy's Energy Information Administration's websites are located at http://www.eia.gov/dnav/pet/pet_pri_fut_s1_d.htm and http://www.eia.gov/dnav/ng/ng_pri_fut_s1_d.htm.

Note 2. The US Board of Governors of the Federal Reserve System's website is located at http://www.federalreserve.gov/datadownload/Choose.aspx?rel=H15.

Note 3. The US Department of Labor's Bureau of Labor Statistics' website is located at $\mathrm{ftp} / / / \mathrm{ftp}$. bls.gov/pub/special.requests/cpi/cpiai.txt. 
Table 1. Summary Statistics

\begin{tabular}{lllll}
\hline & WTI & \multicolumn{3}{l}{ HH } \\
Statistics & real_R(t) & $\Delta\left(\right.$ real_F $\left.\left(t, T_{1}\right)\right)$ & real_R $(t)$ & $\Delta\left(\right.$ real_F $\left.\left(t, T_{1}\right)\right)$ \\
\hline Observations & 1,250 & 1,249 & 1,250 & 1,249 \\
Mean & -5.26 & 0.02 & -1.07 & -0.00 \\
Median & -5.24 & 0.06 & -0.86 & -0.01 \\
Maximum & 264.16 & 15.15 & 1.27 & 1.08 \\
Minimum & -35.32 & -13.24 & -4.94 & -0.94 \\
SD & 12.68 & 1.96 & 1.11 & 0.18 \\
Skewness & 7.70 & -0.07 & -1.24 & -0.12 \\
Kurtosis & 164.76 & 8.90 & 4.75 & 6.65 \\
Jarque-Bera & $1375[0.00]$ & $1815[0.00]$ & $478[0.00]$ & $696[0.00]$ \\
$Q(5)$ & $2515[0.00]$ & $15.76[0.00]$ & $5416[0.00]$ & $10.45[0.06]$
\end{tabular}

Note: The values in brackets are the $p$-values.

$Q(5)$ is a test statistic for the null hypothesis; it indicates that no autocorrelation exists, up to order 5 , for standardized residuals.

Table 2. ADF Unit Root Tests: real_R(t)

\begin{tabular}{lllllll}
\hline \multirow{2}{*}{$\begin{array}{l}\text { Exogenous } \\
\text { variables }\end{array}$} & WTI & \multicolumn{5}{c}{ HH } \\
\cline { 2 - 7 } & lags & $t$-statistics & $p$-values & lags & $t$-statistics & $p$-values \\
\hline None & 6 & $-4.06^{*}$ & 0.00 & 1 & $-2.84^{*}$ & 0.00 \\
Constant & 6 & $-4.50^{*}$ & 0.00 & 1 & $-3.84^{*}$ & 0.00 \\
Constant + trend & 6 & $-4.66^{*}$ & 0.00 & 1 & $-3.97^{*}$ & 0.00
\end{tabular}

Note: ${ }^{*}$ indicates that the unit root hypothesis was rejected at the $1 \%$ significance level.

Table 3. ADF Unit Root Tests: $\Delta\left(\right.$ real $\left._{-} F\left(t, T_{1}\right)\right)$

\begin{tabular}{lllllll}
\hline \multirow{2}{*}{$\begin{array}{l}\text { Exogenous } \\
\text { variables }\end{array}$} & WTI & \multicolumn{5}{c}{$\mathrm{HH}$} \\
\cline { 2 - 7 } & lags & $t$-statistics & $p$-values & lags & $t$-statistics & $p$-values \\
\hline None & 0 & $-37.26^{*}$ & 0.00 & 0 & $-37.85^{*}$ & 0.00 \\
Constant & 0 & $-37.25^{*}$ & 0.00 & 0 & $-37.85^{*}$ & 0.00 \\
Constant + trend & 0 & $-37.23^{*}$ & 0.00 & 0 & $-37.84^{*}$ & 0.00 \\
\hline
\end{tabular}

Note: ${ }^{*}$ indicates that the unit root hypothesis was rejected at the $1 \%$ significance level. 
Table 4. Relationship between demand, price, and income

\begin{tabular}{|c|c|c|c|c|c|}
\hline \multirow[b]{2}{*}{ year } & \multirow[b]{2}{*}{$\begin{array}{l}\text { GWP } \\
\text { [trillion dollars] }\end{array}$} & \multicolumn{2}{|l|}{ crude oil } & \multicolumn{2}{|l|}{ natural gas } \\
\hline & & $\begin{array}{l}\text { price } \\
\text { [dollars/bbl] }\end{array}$ & $\begin{array}{l}\text { demand } \\
\text { [trillion bbl] }\end{array}$ & $\begin{array}{l}\text { price } \\
\text { [dollars/MBTU] }\end{array}$ & $\begin{array}{l}\text { demand } \\
\text { [trillion CBM] }\end{array}$ \\
\hline 2007 & 55.9 & 72.4 & 31.6 & 7.12 & 2.94 \\
\hline 2008 & 61.2 & 99.8 & 31.7 & 8.90 & 3.01 \\
\hline 2009 & 58.0 & 62.1 & 31.2 & 4.16 & 2.94 \\
\hline
\end{tabular}

Note: The GWP was obtained from the United Nations' National Accounts Main Aggregates Database.

The demand of crude oil was obtained from the International Energy Agency's Oil Market Report.

The demand of natural gas was obtained from the BP, Statistical Review of World Energy.

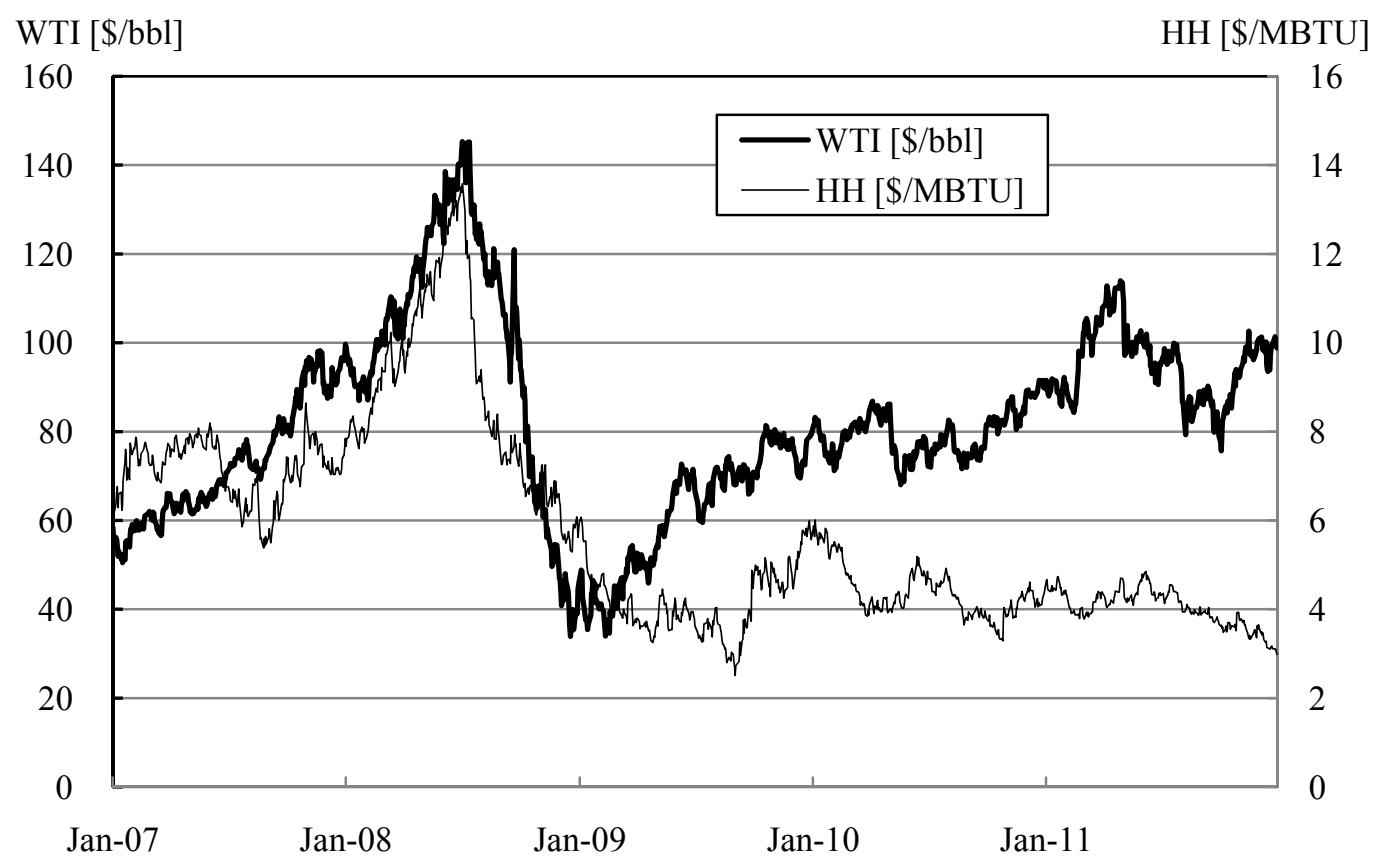

Figure 1. Time-series plots of the prices 